\title{
Peirce's Pragmatic Maxim: Realist or Nominalist?
}

MY PURPOSE HERE is to convince the reader that American pragmatism is not to be simply identified with positivism. By positivism I understand a rather extreme form of nominalism that developed along the lines of classical empiricism. By nominalism I understand any philosophical doctrine that denies the reality of general ideas as part of the ontological structure of things. A nominalistic view of reality makes of it nothing but a set of actual entities each of which is a discrete "absolute" and between which there are no real connections. Such a world is devoid of qualities and of causal relations. It is a world about which only statements of actual contingent fact can be made. To it no necessary statements apply since they are all nothing but logical truths. ${ }^{1}$

Admittedly, this is an incomplete characterization of positivism, but it is sufficient for my purpose since these essential notes of that form of nominalism are what I intend to deny of pragmaticism as developed by Charles S. Peirce. It should also be said at the outset that certain forms of classical rationalism are likewise nominalistic and have developed into a type of positivism all their own. The rationalism of Descartes, with its emphasis upon intuition of clear and distinct ideas, ultimately makes of the world a set of discrete, absolute, and actual entities. The only difference between the rationalism of Descartes and the empiricism of Locke or Hume is that for the former the ultimate building-blocks are abstract ideas while for the latter they are sense data. Both, however, assume the same model for philosophy and, consequently, are formally the same sort of thing. They assume that the world can be analyzed

An earlier version of this chapter appeared as "Peirce's Pragmatic Maxim," in Tijdschrift voor Filosofie, 35 (1973), 505-17. 
adequately into ultimate and discrete entities out of which the real can be reconstructed-and that there is simply nothing more to it! We might call this the fallacy of "nothing but." It is the reductionist fallacy to which analysis is often prone. I do not mean, however, that we should do away with analysis in philosophy; nor do I mean that analysis cannot possibly avoid the "nothing but" mistake. I mean to indicate the historical fact that some philosophers have fallen into this trap and, because of it, have either simply given up the work of synthesis or made it exclusively the work of the human mind without an objective basis. Finally, some have been content to assert the fact of synthesis without being able to give it a satisfactory account.

Now, I intend to deny all this of Peirce's pragmatism. As developed by its founder, pragmatism was meant to be a method of clarifying our ideas and of proceeding in our investigations without falling into the fallacy of "nothing but." It does this by insisting on the reality of general ideas (Peirce calls it an extreme form of "scholastic realism") and by emphasizing the role of vagueness both as a necessary logical component of thought and as an ontological component of the real. An immediate corollary of these two claims is that there can be no such thing as the absolutely incognizable, and, therefore, that the real and the intelligible are co-extensive.

This is the general outline of what I will try to show with respect to Peirce's pragmatic maxim. But before I enter into the properly philosophical discussion, it will be useful to say something about the historical development of pragmatism during Peirce's own lifetime. The reason is that, then and there, a serious misunderstanding about the meaning of the maxim arose among Peirce's philosophical friends and colleagues, and this misunderstanding has led to the rather popular identification of pragmatism with some form of positivism.

Everyone who has tried to teach something or to give a lecture knows how difficult it is to popularize a technical idea without distorting it to some degree. Moreover, there is the constant danger of being misunderstood even about the simplified version. The risk is that the speaker communicates not the idea he had in mind but an entire family of ideas more or less like it. Such a situation is aggravated many times over if the lecturer himself has not clearly understood the technical idea he wishes to popularize. Now, this 
is just what happened with pragmatism. It was popularized by William James, and it was initially misunderstood by him. James thought that he was presenting Peirce's position and explicitly gave him the credit, but the fact is that James's doctrine was not exactly what Peirce had in mind. Thus, Professor R. B. Perry could write that the popular understanding of pragmatism is due largely to James's misunderstanding of Peirce. ${ }^{2}$ As James's books and lectures were read by philosophers in America and Europe a whole family of "pragmatisms" grew up. ${ }^{3}$ Lovejoy, for example, distinguishes some thirteen varieties. ${ }^{4}$ Of these no doubt some are positivistic, and to the extent that they are, any similarity between them and Peirce's position is purely coincidental. Still the stage had been set for positivists to claim that their doctrine is substantially the same as American pragmatism. Thus, when the ideas of the Vienna Circle came to the United States along with several of its members, it was understandable that they should liken their views to those of the "pragmatic" school. Unfortunately, there is no one such thing as "American Pragmatism" except in popular imagination.

As early as 1897 Peirce began to feel uneasy about the version of his doctrine propounded by James. It was in that year that James's Will to Believe, dedicated to Peirce, appeared. In a letter of thanks for the dedication Peirce voiced his reservations (8.249252). By 1900, with the rapid multiplication of "pragmatists," Peirce wrote to James asking for clarification as to who first used the term and what precisely James understood by it (8.253). From that time on, Peirce was seriously engaged in trying to dissociate his own view from those of James and the "ultra-pragmatists" (see 8.212). Besides his letters to James in this sense, he wrote to Calderoni (8.205-213) and published an article in The Monist (5.411437 ) in which he suggests that his position no longer be called "pragmatism" but "pragmaticism" — a name "ugly enough to be safe from kidnappers."

Despite Peirce's protests and his attempts to save "his darling," the term "pragmatism" became popularly associated with James's view. The reason is simple enough-James had the audience and Pierce did not. James was the popular lecturer, the master of English prose, the distinguished Harvard professor, and the man of extraordinary personal charm. Peirce was the technical logician with little patience for popularization, ${ }^{5}$ the writer of turgid and 
elliptical prose, the ex-professor from Johns Hopkins, ${ }^{6}$ and a man of difficult personality. In short, for many reasons, at the time when pragmatism was becoming popular, Peirce found himself isolated in a small Pennsylvania community, without academic standing, without students, without readers, without money, and with failing health. Throughout these difficult years it was James who remained Peirce's most loyal and helpful friend, coming to his assistance again and again financially and through letters of recommendation, ${ }^{7}$ and yet it was James's influence perhaps more than that of any other single man that turned pragmatism away from the intentions of its author.

Let me now turn to the philosophical issues and begin by stating the pragmatic maxim as Peirce first formulated it in $1878^{8}$ and comparing it with one of James's versions. Once the difference has been made clear, I will follow Peirce's efforts to correct James's position or, failing that, to dissociate his opinion from James's. Last, I will point out some of the things implied in Peirce's understanding of pragmatism, namely, realism, the significance of the categories, and, finally, the significance of the theory of interpretants for an understanding of signs.

Peirce's maxim reads as follows:

Consider what effects, that might conceivably have practical bearings, we conceive the object of our conception to have. Then, our conception of these effects is the whole of our conception of the object. (5.402)

Here is James's version of the maxim:

To attain perfect clearness in our thoughts of an object . . . we need only consider ... . what sensations we are to expect from it, and what reactions we must prepare. The ultimate test for us of what a truth means is indeed the conduct it dictates or inspires. But it inspires that conduct because it first foretells some particular turn to our experience which shall call for just that conduct from us. ${ }^{9}$

The general similarity between the two versions is unmistakable. There is even a parallelism in expression. The differences, however, are crucial. In James's version the key words are "perfect clearness," "sensations," and "some particular turn to our experience." Not one of these terms appears in Peirce's text. There the key words are "that might conceivably have practical bearings," "object 
of our conception," and "our conception of the object." James seems to think that the maxim yields perfect clarity of thought. Peirce simply says that it yields the whole of our conception of the object. No doubt, the conscientious application of the maxim will yield a greater grade of clarity than the methods of Descartes or Leibnitz (criticized by Peirce in the same article), still it never yields "perfect" clarity because there is no such thing. All conceptions, because they are signs, are to some extent vague. James thinks sensations are the interpretants of our thought; Peirce holds that only other thoughts (conceptions) can be their interpretants. Hence, Peirce talks of the conceivable practical bearings the object of our thought might have.

In a word, James gives a nominalistic interpretation to thought as basically complexes of sense data; Peirce gives it a realistic interpretation as basically consisting in general ideas, not in singulars. James thinks of practical bearings in terms of particular experiences (this or that actual outcome); Peirce has in mind kinds of experience. James thinks of our relation to our environment as nothing but our action and reaction to it, and thus as consisting solely in what takes place in actual fact. Peirce, on the other hand, thinks of that relation as consisting in more than mere interaction and in more than what merely in fact takes place. He thinks of it as also consisting in what might conceivably happen and in what would happen if certain circumstances were realized. In a word, Peirce makes the possible and the destined constituent of the real along with, of course, the actual. But this means that generals, not merely particulars, have ontological status and must be the ultimate interpretants of thought (see, for example, 5.475-493, $4.536,8.314-315)$.

Finally, it should be pointed out that James had the seed of a proper understanding in his statement of the maxim if he had only followed it through. He was on the right track in pointing out that meaning has a reference to our expectations and to our future conduct. If he had examined more carefully what expectation supposes, he would have seen that it requires the reality of generals since it involves habit and the tendency to take habits. If he had considered more carefully the requirements of conduct, he would have seen that it involves the notion of control, a reference to the future, and alternate kinds of experience. In a word, it requires 
the notion of esse in futuro, what would happen if certain circumstances should be realized. And this, of course, is Peirce's notion of real generals. The least that can be said is, the failure to bring this out leaves James's version open to the positivistic interpretation.

To be fair to James, however, it must be admitted that, although Peirce's 1878 formulation of the pragmatic maxim is accurate enough, and if read carefully, need not yield a nominalistic interpretation, still, some of Peirce's expressions and at least one of his examples are unfortunate and misleading. Take his analysis of "hardness" (5.403ff.). Peirce was to regret this passage and to make every effort in his subsequent writing to correct the mistaken impression it was to give. Let us examine it.

By something hard we evidently mean, says Peirce, that it will not be scratched by many other substances.

The whole conception of this quality, as of every other, lies in its conceived effects. There is absolutely no difference between a hard thing and a soft thing so long as they are not brought to the test. (5.403)

This expression is surely unfortunate especially for one who would not be taken for a nominalist. But it is made even worse by what follows. Peirce asks us to imagine a diamond crystallized within soft cotton where it should remain until completely burned up. No other substance was ever rubbed against it so as to attempt to scratch it. The question is whether it would be correct to call the diamond hard or soft. Peirce answers that it would not be incorrect or even false to call it soft since nothing prevents us from saying that all hard bodies remain soft until they are touched when their hardness increases with the pressure until they are scratched. Such modes of speech "would involve a modification of our present usage of speech with respect to the words hard and soft, but not of their meanings. For they represent no fact to be different from what it is" (5.403).

It is not difficult to see that this analysis plays right into the hands of the positivist. Here practical consequences seem to mean actual sensible results, and facts are assumed to be nothing but actual states of affairs. Facts in this sense are identified with meaning. This, in effect, is what James says, but on Peirce's later reflec- 
tion, this is not what should have been said. Perhaps at the time of this writing Peirce did not fully realize that his own presentation was still marked by the positivistic attitude even though at the time he would not have accepted positivism as a philosophical position. His later remarks seem to bear this out, because he first severely criticizes his example, then goes on to point out that it did not in fact fit the maxim as stated in the same article since that statement stressed that the effects to be considered are all those conceivable, not merely those actually realized. This implies, as Peirce pointed out later, that dispositional properties ("would-be's") are real. It is precisely this that nominalism does not understand or refuses to admit.

Writing to Calderoni in 1905, Peirce remarks that what most distinguishes his pragmaticism from other current forms of pragmatism is its complete break with nominalism.

I myself went too far in the direction of nominalism when I said that it was a mere question of convenience of speech whether we say that a diamond is hard when it is not pressed upon, or whether we say that it is soft it is until pressed upon. I now say that experiment will prove that the diamond is hard, as a positive fact. That is, it is a real fact that it would resist pressure, which amounts to extreme scholastic realism. I deny that pragmatism as originally defined by me made the intellectual purport of symbols to consist in our conduct. On the contrary, I was most careful to say that it consists in our concept of what our conduct would be upon conceivable occasions. (8.208)

Peirce goes on to argue that an absolutely determinate individual would be incognizable and, therefore, unreal. The reason is that it could not function as a sign. ${ }^{10}$

One of the important conclusions from this understanding of the maxim is that although practical consequences in the sense of actual sensible effects are much they are not all in determining the meaning of our concepts. The other important factor is the notion of purpose - the purpose of human reasoning — namely, to regulate and direct human conduct. It has a normative role, and hence the intellectual purport of thought consists in what would happen in appropriate conceivable circumstances, not merely in what does in fact happen on actual occasions. This makes room for a judgment of what ought to happen, that is, of how we ought to act in order 
to achieve whatever might be the ideal purpose of God or Nature in putting us into the universe with the power to reason. Human reasoning is not mere action but the development of an idea. It must be doubted, then, that action can be the sole end and purpose of thought, as the ultra-pragmatists seem to claim (8.209-212).

Writing to James in 1902, Peirce avows that his conception of pragmatism in 1877 was "crude." He had not gotten to the bottom of it until he had established that logic is founded on ethics (of which logic is a higher development), and that ethics in turn is founded on aesthetics.

These three normative sciences correspond to my three categories, which in their psychological aspect, appear as Feeling, Reaction, Thought. . . . The true nature of pragmatism cannot be understood without them. It does not . . take Reaction as the be-all, but it takes the end-all as the be-all, and the End is something that gives its sanction to action. It is of the third category. Only one must not take a nominalistic view of Thought as if it were something that a man had in his consciousness. Consciousness may mean any one of the three categories. But if it is to mean Thought it is more without us than within. It is we that are in it, rather than it in any of us . . . .

This then leads to synechism, which is the keystone of the arch. $(8.256-57)^{11}$

From this point of view, the real cannot simply be a juxtaposition of fundamental building-blocks, no matter how carefully and intricately fitted together. It must be a highly complex set of relations which constitute it, and as such, the real must be of the nature of Thought. Furthermore, the relations that constitute the real cannot be only those that actually obtain but must also include those that might possibly obtain and those that would obtain under specified conditions. The real, in a word, includes a certain order and regularity which is normative of its development. It is the working out of Thought. This is what Peirce means by synechism-the real is a continuous set of relations and not a set of discrete, atomic, actual absolutes. Nor is the real something already absolutely determinate in every respect, for its order and regularity are always open to further development. Tychism, the doctrine that chance or spontaneity is real, is a corollary of synechism. "Value in a world of chance" (to borrow Wiener's expression) sums up well Peirce's 
position with respect to the real. ${ }^{12}$ His categories give it technical expression.

The three fundamental categories for Peirce are: the possible, the actual, and the destined-may-be's, are's, and would-be's. Each category is really distinct from and irreducible to every other even though they cannot be separated in our experience. We can distinguish them in thought by precisive abstraction in a definite, nonreversible order. The possible is first-a monad. The actual is second-a dyad (action-reaction). The destined is third-a triad mediating between what may be and what is. The third category is properly that of thought, regularity, law-likeness, and so is most properly the category of the real. These three categories are both necessary and sufficient to account for the complexity of the real, since with these all higher polyadic relations can be constructed, while without any one of them some relation will be omitted. For example, without the triad as a distinct basic relation, not all threetermed relations can be expressed. $\mathrm{X}$ gives $\mathrm{Y}$ to $\mathrm{Z}$ cannot be accounted for by any combination of dyads and monads.

For Peirce, then, the pragmatic maxim implies realism. General ideas are real, not merely convenient mental constructs as nominalism would have it. This means that the real is more than what is actually the case but also that the real must also include what may be and what surely would be in specified circumstances. All scientific knowledge depends upon such realism and implies that it is so. If it were not, no scientific laws would be possible, and prediction would be nothing more than a sheer guess-it would not even be an "educated" guess. It is impossible here to trace Peirce's arguments for this conclusion, for that would demand a lengthy study of his vast logical works which show that human reasoning involves abduction, deduction, and induction. But I might hint at the line of argument by pointing out that abduction (forming an hypothesis) considers what may be the case and is the Firstness of reasoning; that deduction draws the consequences of the hypothesis - what would be the case in the actual world if the hypothesis were true-and is the Thirdness of reasoning; that induction tests the hypothesis through its consequences against what actually is the case and is the Secondness of reasoning.

Now, it is all this sort of thing that James did not completely understand. Perhaps after this too brief exposition the reader will 
sympathize with him. Be that as it may, James did fail to understand what Peirce meant. In the end James might have judged that Peirce simply was wrong, but that is quite different from not grasping his position in the first place. No doubt, a positivist would have something to say against Peirce's position and he would marshal arguments to refute it, but he could not in honesty any longer simply identify pragmatism with his own position.

As I have mentioned, Peirce made an effort to explain himself to James. Part of that effort included an explanation of his theory of signs as fundamental to the structure of thought. I would like to end by saying something about logical interpretants.

For Peirce, all human thought is a sign relation. Every sign relation is triadic: the relation of its ground to its correlate to its interpretant. Roughly speaking, the ground of a sign is that quality in it which renders it apt to stand for something else. Its correlate is what it so stands for, indicates, or otherwise represents. Its interpretant is what mediates these two and brings them into relation: ${ }^{13}$

an Interpretant is that which the sign produces in the Quasi-mind that is the Interpreter by determining the latter to a feeling, to an exertion, or to a Sign, which determination is the Interpretant. (4.536)

In one place Peirce distinguishes interpretant into emotional, energetic, and logical: the emotional interpretant is the feeling produced by the sign; the energetic interpretant is the effort, physical or mental, elicited by the sign; the logical interpretant is the sign's rational purport. An analysis of the meaning of a concept must take all three into account. It is the logical interpretant that is important for us to consider since it refers to what would be on certain assumptions and therefore is of the nature of a general. Peirce gives an argument why the essence of the logical interpretant must be that of a habit, but that argument need not detain us. I need only remark that while Peirce admits that another concept, proposition, or argument can be $a$ logical interpretant of a concept, he denies that any of these can be the final or ultimate logical interpretant, "for the reason that it is itself a sign of that very kind that has itself a logical interpretant." Only habit can fill the role of ultimate logical interpretant because, although itself of 
the nature of a sign, its interpretant is action. But action is an energetic, not a logical, interpretant because it lacks generality. ${ }^{14}$

Let me return to James's misunderstanding of pragmatism. It might now be stated as a failure to distinguish the energetic from the logical interpretant. While the actual effects determined by a sign are involved in understanding its meaning, they are not its meaning. While action is surely involved in habits, actions are not the habits.

Intellectual concepts, however-the only sign-burdens that are properly denominated 'concepts'-essentially carry some implication concerning the general behavior either of some conscious being or of some inanimate object, and so convey more, not merely than any feeling, but more, too, than any existential fact, namely, the "would-acts," "would-dos" of habitual behavior; and no agglomeration of actual happenings can ever completely fill up the meaning of a "would-be." (5.467)

As I have said, for Peirce, actual effects are much but not all in determining what we mean.

It follows from all that has been said that the meaning of a proposition does not necessarily demand that the action denoted by it be carried out. And yet it is still true that "the sum of the experimental phenomena that a proposition implies makes up its entire bearing upon human conduct" $(5.427)$ because pragmatism

makes thought ultimately apply to action exclusively-to conceived action. But between admitting that and either saying that it makes thought, in the sense of the purport of symbols, to consist in acts, or saying that the true ultimate purpose of thinking is action, there is much the same difference as there is between saying that the artist-painter's living art is applied to dabbing paint upon canvas, and saying that the art-life consists in dabbing paint, or that its ultimate aim is dabbing paint. ... (5.403, note 3$)$

This kind of pragmatism has nothing to do with positivism. Peirce advises us that "instead of merely jeering at metaphysics ... the pragmatist extracts from it a precious essence, which will serve to give light and life to cosmology and physics" (5.423). 


\section{Notes}

1. For a careful historical account of Peirce's move from an early nominalism to a mature realism see the following: Max H. Fisch, "A Chronicle of Pragmaticism, 1865-1879," The Monist, 48 (1964), 441-66, and "Peirce's Progress from Nominalism toward Realism," ibid., 51 (1967), 159-78; Jeffrey R. Di Leo, "Peirce's Haecceitism," Transactions of the Charles S. Peirce Society, 27 (1991), 79-109; John Peterson, "Can Peirce Be a Pragmaticist and an Idealist," ibid., 221-35; Susan Haack, "Extreme Scholastic Realism': Its Relevance to Philosophy of Science Today," ibid., 28 (1992), 19-50; Claudine Engel-Tiercelin, "Vagueness and the Unity of C. S. Peirce's Realism," ibid., 51-82; Paul D. Forster, "Peirce and the Threat of Nominalism," ibid., 691-724; and Joseph Margolis, "The Passing of Peirce's Realism," ibid., 29 (1993), 293-330.

2. The Thought and Character of William James. II. Philosophy and Psychology (Boston: Little, Brown, 1935), p. 409.

3. For example, Papini, Calderoni, Schiller, Royce, Dewey.

4. "The Thirteen Pragmatisms," Journal of Philosophy 5 (1908), $1-12,29-39$.

5. See, for example, his ironic remarks in "Detached Ideas on Vitally Important Topics" (1.616ff.).

6. Peirce taught at Johns Hopkins for only five years (1879-1884).

7. For example, to Harvard for the Chair of Logic. Peirce never got it.

8. See "How to Make our Ideas Clear" (5.388-410).

9. Collected Essays and Reviews, ed. R. B. Perry (New York: Longmans, Green, 1920), pp. 411-12.

10. See 3.93, where Peirce argues that there can be no such thing as a logical atom.

11. For an extended study of Peirce's synechism and tychism, see my Charles S. Peirce: On Norms and Ideals (Amherst: University of Massachusetts Press, 1967), Parts II and III.

12. The title of R. P. Wiener's edition of selected writings of Peirce (Garden City, N.Y.: Doubleday Anchor Books, 1958).

13. See "On a New List of Categories" (1.545ff., especially 1.553).

14. For a brief analysis of the points in this paragraph see my On Norms and Ideals, pp. 209-11. 